\title{
HIGH LEVEL RADIOSONDE ASCENTS AT WYDERABAD DURING JANUARY TO APRIL, 1961
}

\author{
By Anna Manx, F.A.Sc., G. P. Srivastava, B. B. Huddar, \\ N. V. Narayana Rao \\ (Meteorologicaloffice, Poona) \\ AND \\ N. NARAYANA IYER \\ (Nutional Aeronautical Laboratory, Bangalore)
}

Received October 6, 1965

\begin{abstract}
The paper describes a new radiosonde developed at Poona for high altitude balloon soundings and the results of the high level radiosonde ascents taken at Hyderabad as part of the Indo-US Balloon Flight Programme-1961. The temperature data obtained during the programme are presented and compared with the results of the sounding balloon ascents made over Poona and Hyderabad during 1928-35.
\end{abstract}

\section{INTRODUCTION}

A SERIES of high attitude balloon soundings for the study of cosmic rays and of stratospheric aerosols and circulations in the equatorial region, was carried out from Hyderabad early in 1961, jointly by the Atmospheric Circulation Laboratory of the United States Air Force Geophysics Research Directorate and the Cosmic-Ray Research Division of the Tata Institute of Fundamental Research, Bombay. ${ }^{3}$ In view of the importance of meteorological information during the soundings, the India Meteorological Department was invited to take part in the programme, for the study of stratospheric winds and temperatures and of atmospheric electrical potential gradient and conductivity of air in the atmosphere.

Since none of the radiosondes then currently in use in the Department was designed for high altitude operation, the Instruments Division of the Meteorological Office, Poona, was assigned the task of designing and constructing necessary instruments and ground equipment with the desired accuracy and range. The present paper describes the radiosonde and its

A 1 
ground equipment used for the high altitude soundings. The results of the soundings are also discussed.

\section{Programia or OPERATIONS}

During the period January to April 1961, 41 high altitude ascents reaching heights ranging from $20 \mathrm{~km}$. to over $35 \mathrm{~km}$. were made by the US and Indian Scientists from the Begumpet Airport and Osmania University Campus. Large polyethylene balloons were used to carry $100-1,000 \mathrm{~kg}$. pay-loads of electronic, cosmic ray and nuclei counters, inertial impactors and emulsion stacks upto heights of $35 \mathrm{~km}$. The rates of ascent are slow in such soundings, $\mathbf{4 - 6} \mathrm{km}$. $/ \mathrm{hr}$. at launch increasing to $20-22 \mathrm{~km}$. $/ \mathrm{hr}$. near the ceiling. The radiosondes attached to these balloons were found to give erroneous readings as a result of their proximity to the large balloons and pay-loads especially the black TIFR balloons, and insufficient ventilation on account of the low rates of ascent. Reliable temperature observations could therefore be made only when long load lines were used and the rate of ascent sufficiently high. Even then, the temperature data appeared to be doubtful. Only temperature data obtained independently with smaller high altitude rubber balloons are considered in this paper.

A series of $\mathbf{4 5}$ radiosonde ascents were made during the programme with small rubber balloons. Upper wind observations with radio-theodolites and atmospheric electricity observations ${ }^{2}$ with telemetering potential gradient and conductivity sondes were also made.

\section{Description of the Radiosonde}

'The radiosonde (Figs. I and 2) is an improved model of the timeinterval type pulse counting radiosonde of the India Meteorological Departw ment. $^{3}$ The distribution of the contacts in the new sonde is shown in Fig. 3. $R_{1} R_{2}$ are the fixed reference contacts; the pressure contact $\mathbf{P}$ moves over 80 per cent of the cycle and covers a range of $1,050-52 \mathrm{mb}$. The temperature contact $\mathrm{T}$ moves over $65 \%$ of the cycle and covers a range of +40 to $-90^{\circ}$. OM is the rotating helix contact that switches on the fixed reference, temperature and pressure signals in that order.

The paper fan which drives the contacting helix in the F-type radiosonde was replaced by $\boldsymbol{a}$ small electric motor in the new sonde (Fig. 2). The motor consists of a permanent bar magnet, rotating inside a rectangular coil. An eccentric cam on the shaft of the magnet vibrates a spring against an adjustable contact; the spring is weighted to have a natural frequency of about 1,750 vibrations per minute and the motor revolves with 


\section{Radiosonde Ascents at Hyderabad during January to April, 1961}

great accuracy at the same number per minute, its speed being practically independent of the voltage within limits and changing only slowly with temperature. The motor is run from $\boldsymbol{a} 7 \cdot 5$ volt dry battery and develops ample power.

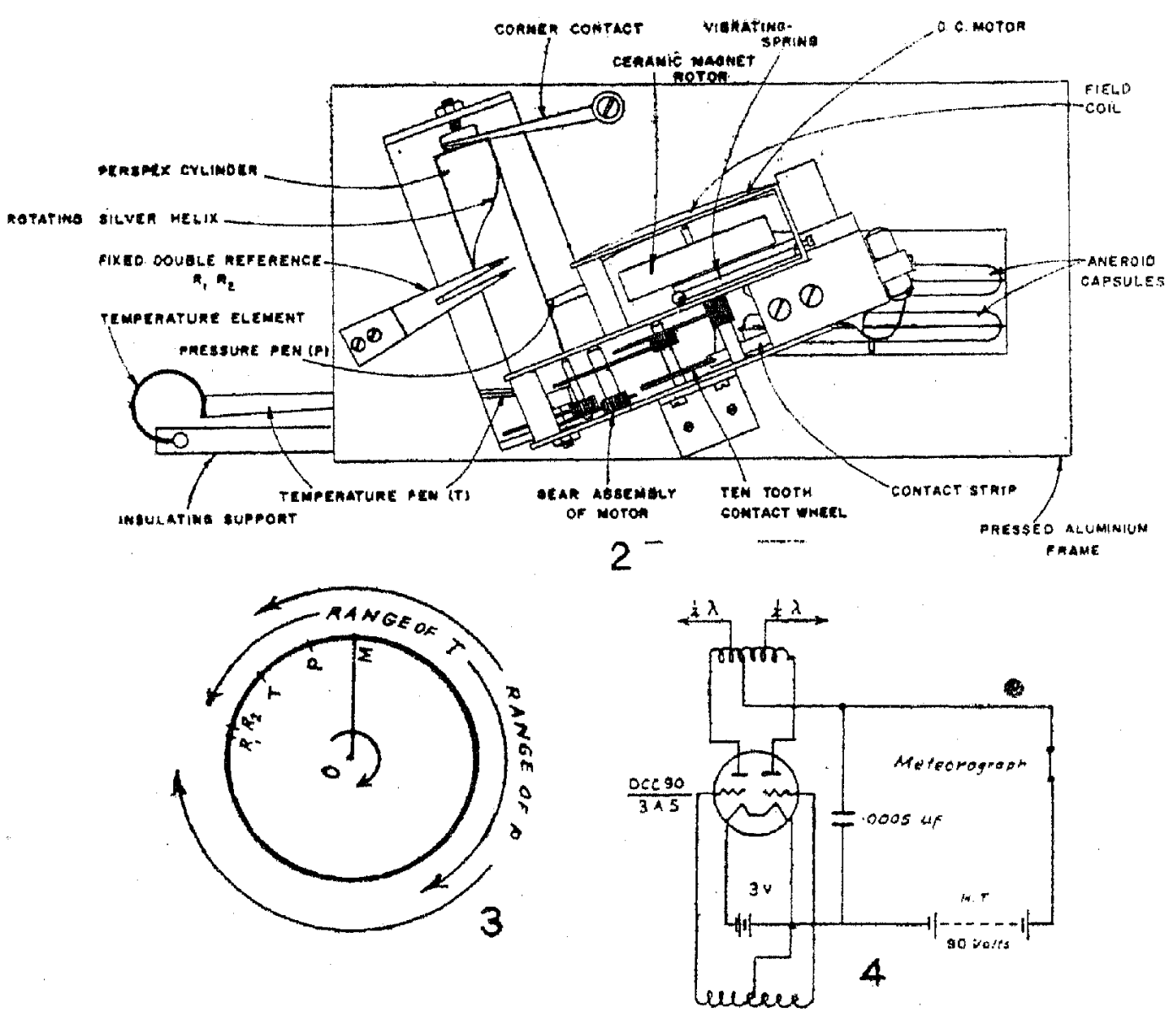

FIGs. $2-4$

The rotating helix, a thin silver wire wound in a screw thread cut on a polished clear perspex insulating cylinder, is driven by the electric motor through four reduction gears $\frac{1}{7}: \frac{1}{5}: \frac{1}{5}: \frac{x}{5}$ at a speed of 2 revolutions per minute. A 10-tooth contact wheel breaks up the time interval to $\mathbf{1 . 2 5 0}$ pulses far one complete rotation of the helix. The distribution of the contacts is such that 980 pulses are available for pressure and 780 for temperature, giving a precision in pressure measurement of $2 \mathrm{mb}$. in the higher and $0.5 \mathrm{mb}$. in the lower ranges and in temperature of $0.15^{\circ} \mathrm{C}$.

The pressure element is a double aneroid capsule, $5 \mathrm{~cm}$. in diameter, of beryllium copper designed for increased sensitivity at low pressures, and 
the temperature element a single semicircular coil of 'highflex $45^{\prime}, 0.25 \mathrm{~mm}$. thick and $13 \mathrm{~mm}$. wide, thermally insulated from the pressed aluminium frame by a piece of 'hylam' rod $5 \mathrm{~cm}$. long. A double-walled aluminium radiation shield protects the element from direct radiation. The radiation errors of the temperature element within the shield were determined in the laboratory and found to be negligible; being of the order of $1.0^{\circ} \mathrm{C}$. at $5 \mathrm{mb}$. for elevation angles of the sun of $55^{\circ}$.

The radio transmitter (Fig. 4) operating on $67 \mathrm{mc}$. is a single valve twin triode, in push-pull circuit with a power output of $700 \mathrm{mw}$. The HT power supply consists of two $90 \mathrm{~V}$ dry batteries connected in parallel. The transmitting aerial is a centre-fed halfwave wire stretched vertically. The meteorograph and transmitter with batteries are fitted inside two themocole-insulated aluminium boxes, placed one above the other. The whole instrument weighs about 2,000 $\mathrm{gm}$.

The radiosonde receiver is of the super-regenerative type, giving about $70 \mathrm{~mA}$ current at the output, for both strong and weak signals. The highspeed recorder was specially designed to take up the increased number of pulses at the rate of 50 pulses per second and record on a continuously moving narrow paper tape. The receiving antenna is the standard three half-wave aerials at right angles to each other.

The radiosondes were individually calibrated over the whole pressure and temperature range, the calibration being done in air, with the pressure and temperature lowered simultaneously. The control correction before release was determined in a special insulated chamber with built-in radio transmitter.

The balloons used were 875 or 1,500 gm. rubber balloons made by Swastik Rubber Products, Poona; 1,250 Beritex or Japanese 2,000 and 3,000 gm. balloons were also used on a few occasions.

\section{ReSUlts}

The temperature data obtained at Hyderabad during the three months February to April 1961 are given in Figs. 5 and 6, where temperature in ${ }^{\circ} \mathrm{C}$. are plotted against height in $\mathrm{km}$. The mean values for the corresponding months obtained from sounding balloon ascents over the region ${ }^{4,5}$ in 1928-35 are also plotted as a thicker trace in the same diagram,

The monthly mean temperatures for February, March and April 1961, obtained at Hyderabad, are given in Table $I$ along with the normals ${ }^{5}$ from 
Radiosonde Ascents at Hyderabad during January to April, 1961

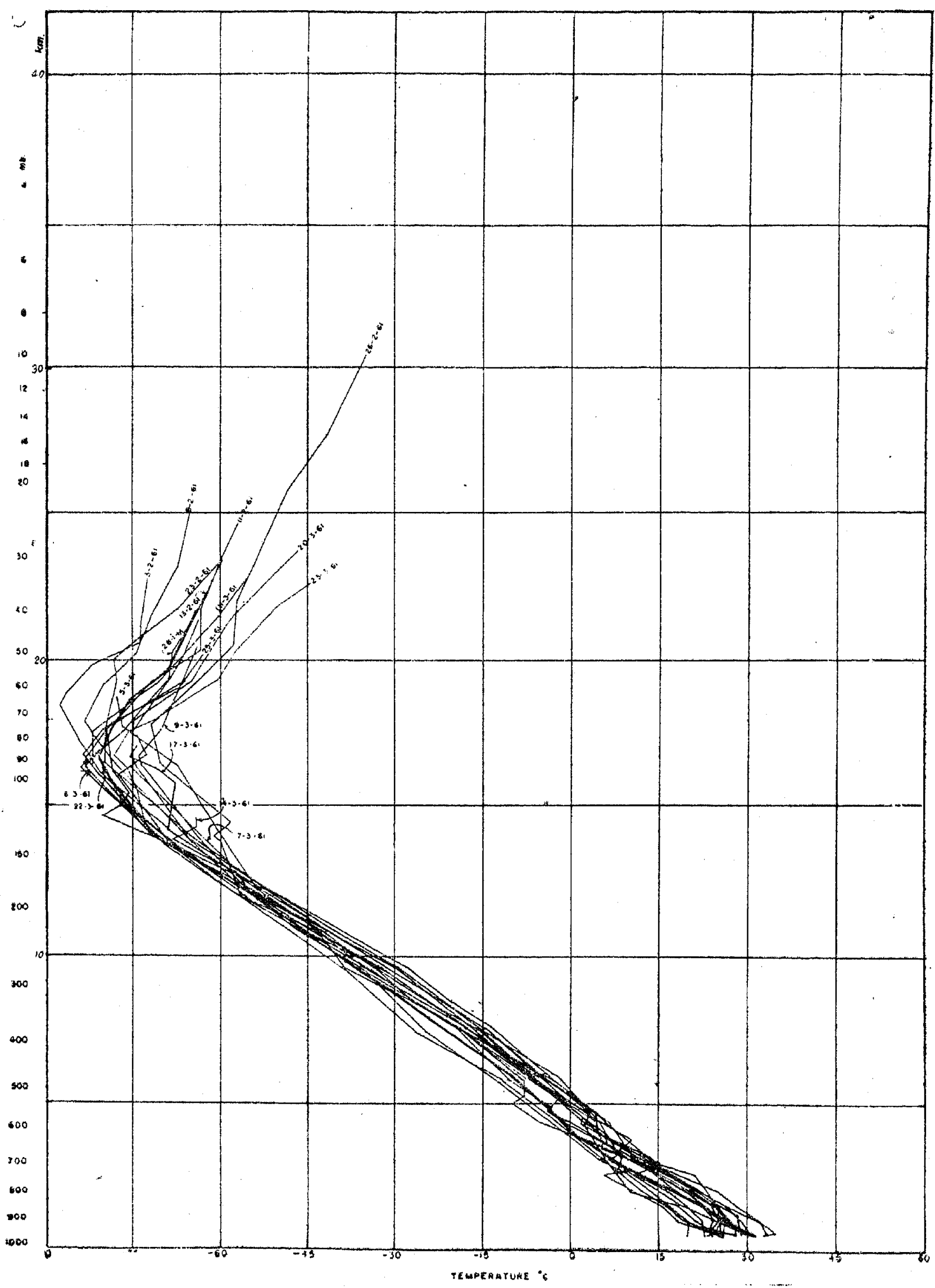

Fịg. 5 


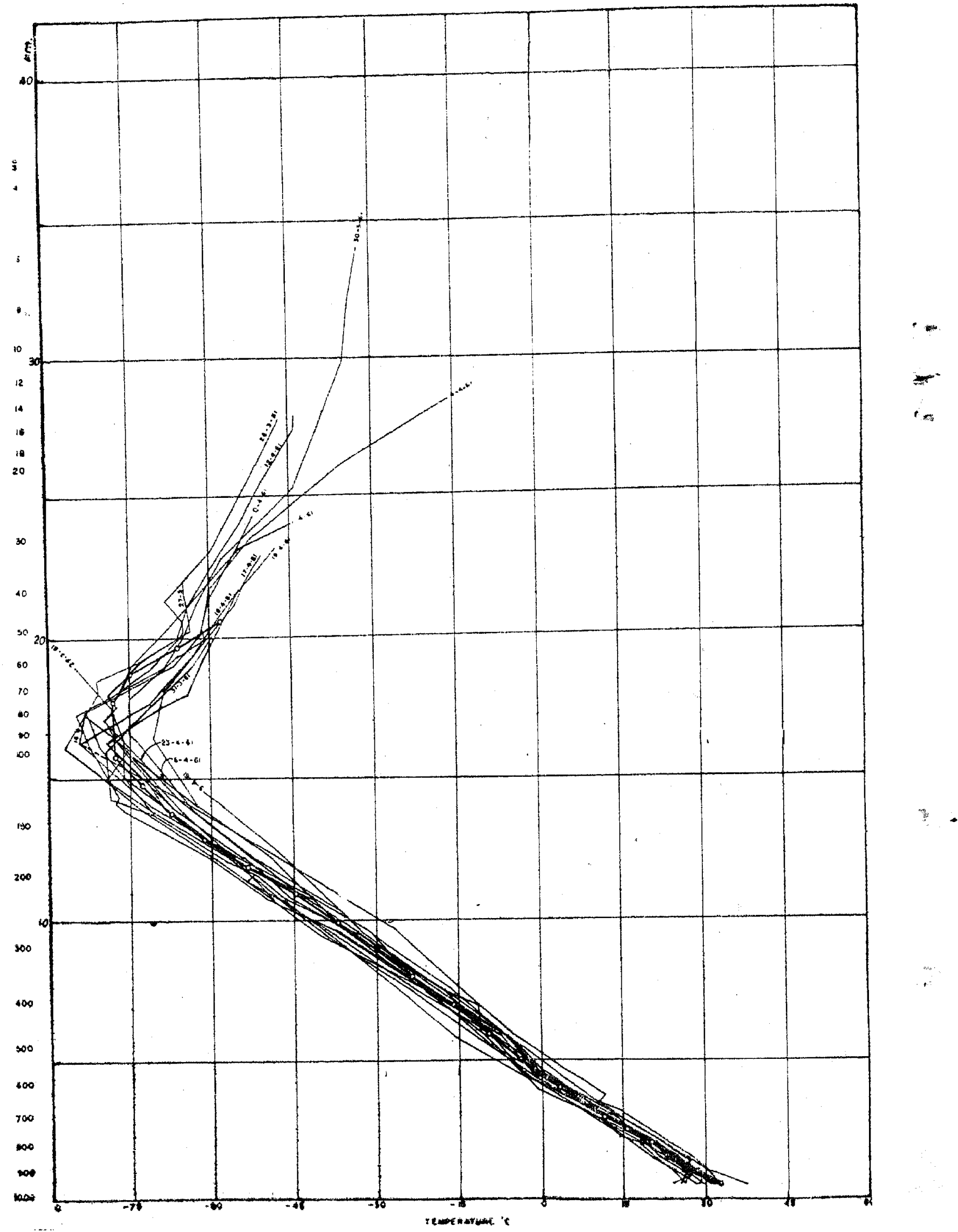

FTo. 6 
TABLE I. Mean monthly temperatures over Poona and Hyderabad

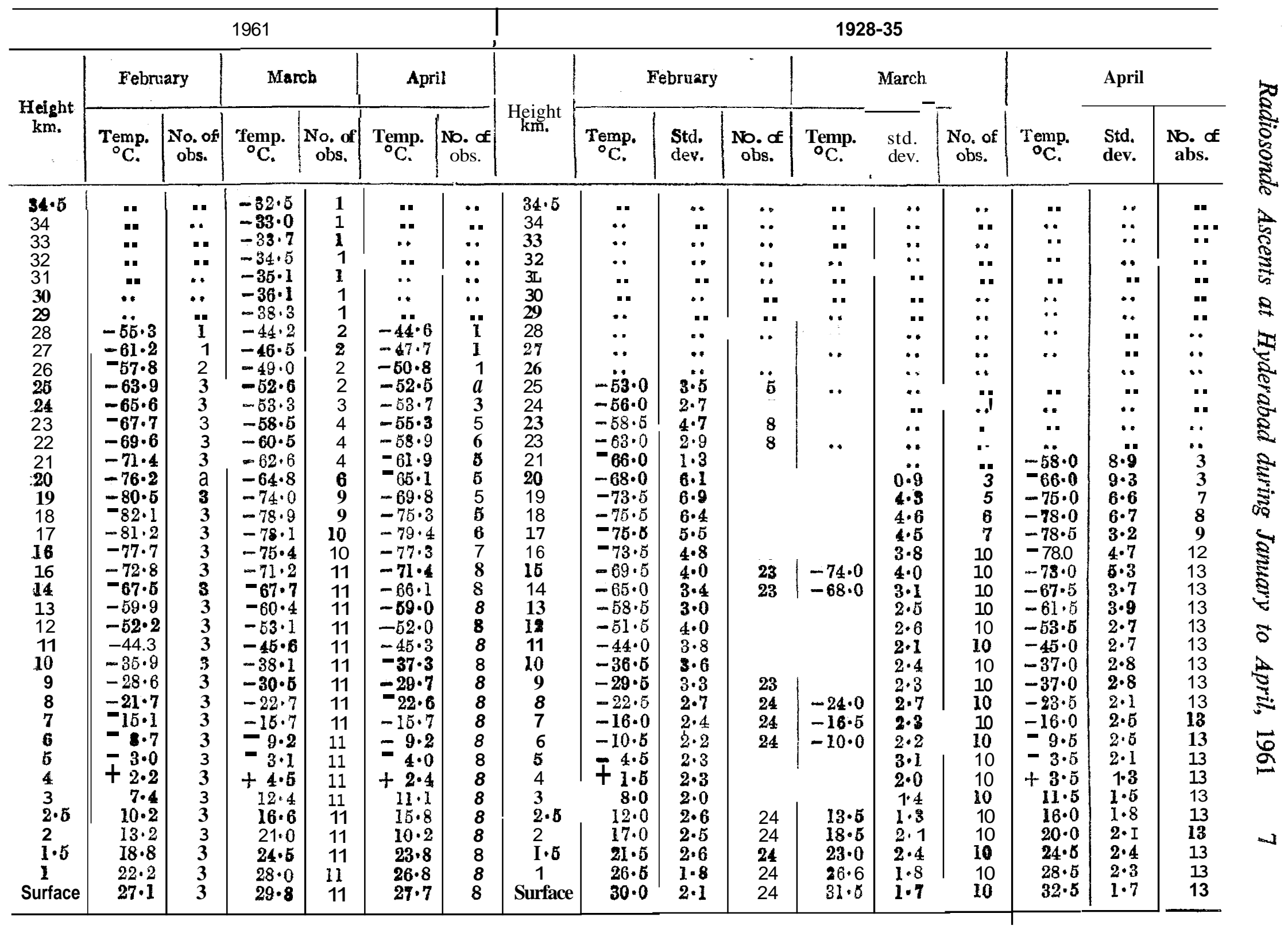


sounding balloon data for Poona and Hyderabad for the corresponding months obtained during 1928-35. All the radiosonde data obtained with small balloons during March and April at Hyderabad are included in the table. In the earlier soundings during February, the sonde which was under test did not function up to $50 \mathrm{mb}$. on most of the occasions and therefore only $\mathbf{3}$ out of $\mathbf{2 1}$ soundings taken in February have been included in the table. The data obtained during March and April 1961 with the new sonde and the earlier sounding balloon data for the corresponding months show fairly good agreement.

\section{ACKNOWLEDGEMENT}

Our thanks are due to Sarvashri J, C. Bhattacharyya, M. S. Swaminathan, S. Gopinath, R. R. Wagholikar and N. D. Mishram and others of the Instruments Division, Poona, for their invaluable assistance in the design of the radiosonde and the construction and calibration of adequate numbers of instruments in the very short time available for the soundings at Hyderabad and for assistance in the actual soundings. Our thanks are also due to the National Physical Laboratory, New Delhi, and the National Chemical Laboratory, Poona, which supplied special ceramic magnets for the electric motors and to Mr. H. H. Bindon of the Canadian Meteorological Service for making available special stainless steel for the vibrating reed of the motor.

We are grateful to the Director-General of Observatories for permission to publish this paper.

\section{REFERENCES}

1. Chagnon, C.w.

... "Joint Indo-United States Balloon Flight Programme-1961," Research Report of Space Physics Laboratory, Air Force Cambridge Research Laboratories, Hanscom Field, Mass., 1962.

2. Mani, A. and Huddar, B. B. "Atmospheric electricity measurements in the upper air over Poona," Proc. Ind. Acad. Sci., 1965, 61, 322.

3. Venkiteshwaran, S.P., Thatte, R.P. and Keshavamurthy, A.

4. Ramanathan, K. R. and Ramakrishnan, K. P.

"The fan-type radiometeorograph of the India Meteorological Department," I.M.D. Scientific Notes, 1948, 9, No. 113,

'Discussion of results of sounding balloon ascents at Poona and Hyderabad during the period October 1928 to December 1931," Memoirs of the India Met. Dept., 26, Part IV, 51-5.

5. India Meteorological Department Upper Air Data, 1939, 12, Part A, 211, 